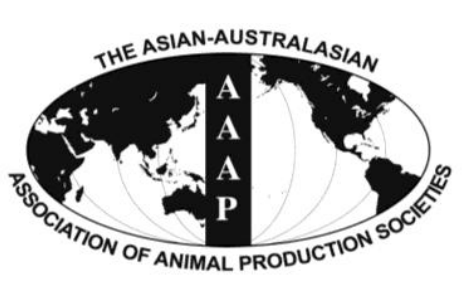

Open Access

Asian Australas. J. Anim. Sci.

Vol. 27, No. 10 : 1399-1405 October 2014

http://dx.doi.org/10.5713/ajas.2014.14016

\author{
www.ajas.info
}

pISSN 1011-2367 elSSN 1976-5517

\title{
Genetic Diversity and Relationships of Korean Chicken Breeds Based on 30 Microsatellite Markers
}

\author{
Sangwon Suh ${ }^{1, a}$, Aditi Sharma ${ }^{2, a}$, Seunghwan Lee ${ }^{2, a}$, Chang-Yeon Cho ${ }^{1}$, Jae-Hwan Kim ${ }^{1}$, Seong-Bok Choi ${ }^{1}$, \\ Hyun Kim ${ }^{1}$, Hwan-Hoo Seong ${ }^{1}$, Seong-Hum Yeon ${ }^{2}$, Dong-Hun Kim ${ }^{1}$, and Yeoung-Gyu Ko ${ }^{1}$ ** \\ ${ }^{1}$ Animal Genetic Resources Station, National Institute of Animal Science, RDA, Namwon 590-832, Korea
}

\begin{abstract}
The effective management of endangered animal genetic resources is one of the most important concerns of modern breeding. Evaluation of genetic diversity and relationship of local breeds is an important factor towards the identification of unique and valuable genetic resources. This study aimed to analyze the genetic diversity and population structure of six Korean native chicken breeds $(n=300)$, which were compared with three imported breeds in Korea $(n=150)$. For the analysis of genetic diversity, 30 microsatellite markers from FAO/ISAG recommended diversity panel or previously reported microsatellite markers were used. The number of alleles ranged from 2 to 15 per locus, with a mean of 8.13. The average observed heterozygosity within native breeds varied between 0.46 and 0.59 . The overall heterozygote deficiency $\left(F_{\mathrm{IT}}\right)$ in native chicken was $0.234 \pm 0.025$. Over $30.7 \%$ of $F_{\mathrm{IT}}$ was contributed by within-population deficiency $\left(F_{\mathrm{IS}}\right)$. Bayesian clustering analysis, using the STRUCTURE software suggested 9 clusters. This study may provide the background for future studies to identify the genetic uniqueness of the Korean native chicken breeds. (Key Words: Korean Native Chicken, Microsatellite, Genetic Diversity, Genetic Relationship)
\end{abstract}

\section{INTRODUCTION}

Native or local breeds are nowadays usually characterized by their geographical distribution. Evaluation of genetic diversity and relationship of local breeds is an important factor towards the identification of unique and valuable genetic resources.

The Korean native chicken breeds, owing to their bad commercial performance, were ignored during many years until recently when the demand for native chicken increased suddenly, as it suits the Korean palate and as the NIAS (National Institute of Animal Science, Korea) realized the necessity of conserving native breeds. In order to meet the commercial drawbacks of native chickens low economic efficiency, commercial breeds were developed. Along with the indigenous and commercial chicken breed, Korea also

\footnotetext{
* Corresponding Author: Yeoung-Gyu Ko. Tel: +82-63-620-3535, Fax: +82-63-620-3592, E-mail: kog4556@korea.kr

${ }^{2}$ Hanwoo Experiment Station, Pyeongchang 232-950, Korea.

${ }^{\text {a }}$ S. Suh, A. Sharma, and S. Lee, contributed equally to this work. Submitted Jan. 6, 2014; Revised Mar. 21, 2014; Accepted Jun. 3, 2014
}

has many other breeds of chicken, which were imported in the country in the early 20th century from Europe, North America and Japan. Due to being raised by different farmers belonging to different communities and different geographical locations across Korea, the local chicken breeds have plumage and shank colors different from each other.

Korean native chicken has several plumage colors (White, Black, Yellowish-brown, Grayish-brown, Reddishbrown), but all have a single comb, and their shin has brown, dark green or black colors. Tail feathers of native chickens are relatively longer than exotic breeds. As well as, there is a unique native chicken breed called Yeonsan Ogye, which has not only plumage, comb, beak, shin, claw but also the muscle, bone and intestinal organs all in black color. In 1980 this breed was registered as a natural monument (No. 265) and maintained as one of the native chicken breeds (MAF, 2004). Six Korean native chicken breeds have been documented in the DAD-IS (Domestic Animal Diversity Information System, http://dad.fao.org/) of the FAO (Food and Agriculture Organization), and have been 
conserved with about 2,000 chickens being maintained for each breed as a genetic resource.

Evaluating the genetic diversity and genetic structure of these breeds is an important step towards identifying and conserving valuable genetic resources.

Genetic marker polymorphisms are a certain way of assessing the biodiversities within and among chicken breeds. Different genetic markers have been used for the evaluation of genetic variability in poultry including DNA fingerprinting (Dunnington et al., 1994), random amplified polymorphic DNA (Smith et al., 1996) and microsatellites (Crooijmans et al., 1995; Vanhala et al., 1998; Wimmers et al., 2000). Microsatellites are being used in diversity studies due to their codominant, highly polymorphic nature and availability throughout the genome and thus microsatellites are identified as reliable markers in chickens (Hillel et al., 2003; Tando et al., 2007). Clustering individuals into population groups based on their genotypic data will allow the interpreting of group relations without any prior knowledge of breeds.

The aims of this study was to characterize the genetic diversity of Korean native chicken breeds and to investigate the relationships among six native chicken breeds recorded by FAO (DAD-IS, http://dad.fao.org), based on 30 microsatellite markers.

\section{MATERIALS AND METHODS}

\section{Sampling and DNA extraction}

A total of 450 chickens belonging to 9 different breeds were sampled for this study. These nine breeds included six Korean native chicken breeds (Korean Reddish Brown, KR; Korean Yellowish Brown, KY; Korean Grayish Brown, KG; Korean Black, KB; Korean White, KW; Korean Ogye, KO) and three imported breeds (White Leghorn, WL; Rhode Island Red, RI; Cornish, CN), with 50 individuals per breed respectively. Approximately $1 \mathrm{~mL} /$ chicken of ulnar veinous blood was collected in anticoagulant coated tubes and stored at $-20^{\circ} \mathrm{C}$. Genomic DNA was extracted from the whole blood using the MagExtractor (TOYOBO, Osaka, Japan) commercial DNA extraction kit. The DNA concentrations were quantified by NanoDrop 1000 Spectrophotometer (NanoDrop Technologies Inc, Wilmington, DE, USA) and samples were diluted to a final concentration of $10 \mathrm{ng} / \mu \mathrm{L}$ in Tris-EDTA buffer ( $\mathrm{pH}$ 8.0).

Polymerase chain reaction and microsatellite genotyping Thirteen microsatellite (MS) markers (ADL0278, LEI0094, LEI0166, LEI0192, MCW0016, MCW0037, MCW0078, MCW0111, MCW0165, MCW0183, MCW0206, MCW0295, MCW0330) were chosen from the FAO/MoDAD (2004), whereas the previously reported (Chen et al., 2008; Kaya and Yildiz, 2008; Muchadeyi et al.,
2007; Osman, et al., 2006; Tadano, et al., 2007) other 17 MS markers (ADL0176, ADL0262, ADL0267, LEI0092, LEI0096, LEI0099, LEI0135, LEI0209, MCW0103, MCW0145, MCW0193, MCW0214, MCW0233, MCW0240, MCW0252, MCW0301, MCW0322) were chosen based on their high heterozygosity, chromosomal location, wide range of alleles and ease of amplification in multiplex polymerase chain reaction (PCR).

DNA was amplified by a standard PCR protocol with Negative dye PCR PreMix (Bioneer, Daejeon, Korea). The ABI 3130xl Genetic Analyzer (Applied Biosystems, Foster, CA, USA) was used for the capillary electrophoresis of the PCR product. The estimation of allele size was performed using GeneMapper Software ver. 4.0 (Applied Biosystems, Foster, CA, USA). The allele data thus retrieved was subjected to further statistical analysis.

\section{Statistical analysis}

The genetic variation within each breed was evaluated and compared. The total number of alleles (NA) at each locus, the respective allele frequency, observed $\left(H_{\mathrm{Obs}}\right)$ and expected $\left(H_{\text {Exp }}\right)$ heterozygosities, and polymorphism information content (PIC) value for each breed across the locus were calculated using the GenAlEx 6.4 (Peakall and Smouse, 2006) and Cervus ver. 3.0.3 (Kalinowski et al., 2007).

The $F_{\text {IT }}$ (inbreeding coefficient of an individual relative to the total population), $F_{\mathrm{ST}}$ (the effect of subpopulations compared with the total populations) and $F_{\text {IS }}$ (inbreeding coefficient of an individual relative to the subpopulation) and values for each breed were calculated by the estimator of Weir and Cockerham (1984) using the FSTAT (Ver. 2.9.3, Goudet, 2001). The $D_{\text {A }}$ genetic distance (Nei et al., 1983) was calculated and phylogenetic trees were estimated using with DISAPN program (Ota, 1993).

The genetic structure and the degree of admixture of nine chicken populations were investigated using the Bayesian clustering procedure of STRUCTURE ver. 2.3 (Pritchard et al., 2000). We carried out 50 independent runs for each $\mathrm{K}$ value ranging from 2 to 11 . For all runs, the admixture models with a burn-in period of 20,000 iterations followed by 100,000 iterations of Markov chain Monte Carlo algorithm. To identify the most probable groups $(K)$ that best fit the data, we used the STRUCTURE Harvester (Earl and von Holdt, 2012), which implements the Evanno method (Evanno et al., 2005). The program CLUMPP ver. 1.1 (Jakobsson and Rosenberg, 2007) was used to align the 50 repetitions of the each $K$. The CLUMPP out files were visualized using DISTRUCT ver. 1.1 (Rosenberg, 2004).

\section{RESULTS}

Microsatellite polymorphisms, within and between 


\section{populations}

The microsatellite polymorphism, evaluated by the NA per locus, the mean heterozygosity, PIC and $F_{\text {IS }}$ (inbreeding coefficient) for each breed are described in Table 1. A total of 244 alleles were observed at the 30 microsatellite loci distributed in 450 chickens representing 9 chicken populations. All the microsatellite loci typed were polymorphic. The NA per locus ranged from 2 (MCW0103) to 15 (LEI0192), with a mean of 8.13 alleles. The mean of $H_{\text {Exp }}$ across loci was 0.696 , with estimates per locus ranging from 0.305 (MCW0103) to 0.857 (LEI0209). For $H_{\text {Obs, }}$, the mean for all loci was 0.495 , and the range was between 0.278 (MCW0103) and 0.680 (MCW0145). In this study most of the loci had high PIC values (PIC>0.5), with the exception of LEI0166 (0.454), MCW0078 (0.345), and MCW0103 (0.258). Of the 30 loci, four loci had negative coefficients and the mean $F_{\text {IS }}$ was moderate $(0.102)$.

The breed statistics generated by the 30 microsatellite markers in nine chicken breeds are shown in Table 2 . The mean NA in each breed ranged from $3.43 \pm 0.33$ (WL) to $5.43 \pm 0.40$ (KR). The two most diverse breeds were the KR and $\mathrm{KB}$, which had the highest mean $H_{\operatorname{Exp}}(0.624$ and 0.629), $H_{\mathrm{Obs}}(0.548$ and 0.591$)$, and PIC (0.575 and 0.569), respectively. The imported breed WL was the least diverse population, having the lowest mean $H_{\text {Exp }}(0.416), H_{\text {Obs }}$ (0.326), and PIC (0.371).

The mean $F_{\mathrm{IS}}, F_{\mathrm{ST}}$, and $F_{\mathrm{IT}}$ Korean native and imported chicken breeds are given in Table 3 . The overall inbreeding coefficient $\left(F_{\mathrm{IT}}\right)$ observed for all nine breeds was $0.307 \pm 0.021$. High $F_{\text {IT }}$ estimated $(0.438 \pm 0.024)$ was observed in the imported flocks. Between-population variability $\left(F_{\mathrm{ST}}\right)$ was $0.351 \pm 0.021$ in this group of populations.

An $F_{\text {IT }}$ of $0.234 \pm 0.025$ and an $F_{\text {ST }} 0.142 \pm 0.010$ were observed in the Korean native flocks. The imported flocks showed higher genetic differentiation between breeds than the Korean native chicken breeds. The $F_{\text {IS }}$ estimate for imported flocks was higher $(0.134 \pm 0.027)$ than that of the

Table 1. Descriptive statistics of the 30 microsatellite loci across nine chicken breeds

\begin{tabular}{|c|c|c|c|c|c|c|}
\hline Locus & Allele range (bp) & NA & $H_{\operatorname{Exp}}$ & $H_{\mathrm{Obs}}$ & PIC & $F_{\text {IS }}$ \\
\hline ADL0176 & $186-208$ & 8 & 0.739 & 0.295 & 0.703 & 0.473 \\
\hline ADL0262 & $105-109$ & 3 & 0.628 & 0.518 & 0.557 & 0.011 \\
\hline ADL0267 & $99-119$ & 11 & 0.630 & 0.322 & 0.595 & 0.341 \\
\hline ADL0278 & $109-121$ & 6 & 0.706 & 0.540 & 0.649 & -0.043 \\
\hline LEI0092 & $236-256$ & 8 & 0.760 & 0.584 & 0.721 & 0.015 \\
\hline LEI0094 & $245-283$ & 12 & 0.856 & 0.653 & 0.839 & -0.040 \\
\hline LEI0096 & $216-242$ & 11 & 0.761 & 0.624 & 0.729 & -0.024 \\
\hline LEI0099 & $115-131$ & 6 & 0.648 & 0.362 & 0.607 & 0.182 \\
\hline LEI0135 & $132-144$ & 6 & 0.667 & 0.430 & 0.605 & 0.108 \\
\hline LEI0166 & $340-356$ & 4 & 0.524 & 0.367 & 0.454 & 0.046 \\
\hline LEI0192 & $258-308$ & 15 & 0.791 & 0.567 & 0.770 & 0.109 \\
\hline LEI0209 & $137-175$ & 12 & 0.857 & 0.673 & 0.840 & -0.030 \\
\hline MCW0016 & $140-154$ & 8 & 0.768 & 0.587 & 0.730 & -0.039 \\
\hline MCW0037 & $152-158$ & 4 & 0.636 & 0.488 & 0.563 & 0.036 \\
\hline MCW0078 & $131-145$ & 6 & 0.389 & 0.294 & 0.345 & 0.095 \\
\hline MCW0103 & $269-273$ & 2 & 0.305 & 0.278 & 0.258 & 0.021 \\
\hline MCW0111 & 98-112 & 6 & 0.685 & 0.464 & 0.621 & 0.184 \\
\hline MCW0145 & $181-217$ & 14 & 0.811 & 0.680 & 0.787 & 0.059 \\
\hline MCW0165 & $114-118$ & 3 & 0.653 & 0.289 & 0.579 & 0.446 \\
\hline MCW0183 & $282-322$ & 14 & 0.769 & 0.561 & 0.740 & 0.107 \\
\hline MCW0193 & $299-317$ & 10 & 0.782 & 0.584 & 0.762 & 0.056 \\
\hline MCW0206 & $215-245$ & 10 & 0.839 & 0.585 & 0.819 & 0.183 \\
\hline MCW0214 & 274-304 & 11 & 0.761 & 0.576 & 0.730 & -0.029 \\
\hline MCW0233 & $205-217$ & 5 & 0.595 & 0.422 & 0.531 & 0.030 \\
\hline MCW0240 & $171-195$ & 10 & 0.824 & 0.576 & 0.800 & 0.201 \\
\hline MCW0252 & $287-303$ & 8 & 0.710 & 0.589 & 0.680 & -0.010 \\
\hline MCW0295 & 84-98 & 7 & 0.751 & 0.541 & 0.710 & 0.051 \\
\hline MCW0301 & $261-289$ & 14 & 0.775 & 0.474 & 0.743 & 0.205 \\
\hline MCW0322 & $250-258$ & 5 & 0.617 & 0.422 & 0.546 & 0.194 \\
\hline MCW0330 & $267-287$ & 5 & 0.631 & 0.504 & 0.566 & 0.118 \\
\hline Over all & - & 8.13 & 0.696 & 0.495 & 0.653 & 0.102 \\
\hline
\end{tabular}

NA, number of alleles per locus, across breeds; $H_{\text {Exp }}$, expected heterozygosity frequency, average across breeds; $H_{\mathrm{Obs}}$, observed heterozygosity frequency, average across breeds; PIC, polymorphism information content, average across breeds; $F_{\mathrm{IS}}$, inbredding coefficient index, average across breeds. 
Table 2. Diversity parameters in Korean native and imported chicken breeds

\begin{tabular}{lccccc}
\hline Breed & NA & MNA & $H_{\text {Exp }}$ & $H_{\text {Obs }}$ & PIC \\
\hline KR & 163 & $5.43 \pm 0.40$ & $0.624 \pm 0.031$ & $0.548 \pm 0.035$ & $0.575 \pm 0.031$ \\
KY & 161 & $5.37 \pm 0.41$ & $0.618 \pm 0.029$ & $0.536 \pm 0.036$ & $0.560 \pm 0.029$ \\
KG & 121 & $4.03 \pm 0.26$ & $0.548 \pm 0.033$ & $0.518 \pm 0.036$ & $0.488 \pm 0.031$ \\
KB & 155 & $5.17 \pm 0.36$ & $0.629 \pm 0.024$ & $0.591 \pm 0.032$ & $0.569 \pm 0.026$ \\
KW & 121 & $4.03 \pm 0.28$ & $0.607 \pm 0.023$ & $0.557 \pm 0.033$ & $0.536 \pm 0.026$ \\
KO & 124 & $4.13 \pm 0.30$ & $0.559 \pm 0.032$ & $0.464 \pm 0.040$ & $0.499 \pm 0.030$ \\
WL & 103 & $3.43 \pm 0.33$ & $0.416 \pm 0.048$ & $0.326 \pm 0.039$ & $0.371 \pm 0.043$ \\
RI & 107 & $3.57 \pm 0.25$ & $0.508 \pm 0.032$ & $0.442 \pm 0.032$ & $0.446 \pm 0.303$ \\
CN & 111 & $3.70 \pm 0.28$ & $0.509 \pm 0.029$ & $0.475 \pm 0.032$ & $0.444 \pm 0.028$ \\
Overall & 244 & $4.32 \pm 0.12$ & $0.696 \pm 0.023$ & $0.495 \pm 0.022$ & $0.653 \pm 0.025$ \\
\hline NA, & & & &
\end{tabular}

NA, number of alleles; MNA, mean number of alleles with standard error; $H_{\text {Exp. }}$ expected heterozygosity frequency, average across breeds; $H_{\mathrm{obs}}$, observed heterozygosity frequency, average across breeds; PIC, polymorphism information content, average across breeds; KR, Korean Reddish Brown; KY, Korean Yellowish Brown; KG, Korean Grayish Brown; KB, Korean Black; KW, Korean White; KO, Korean Ogye; WL, White Leghorn; RI, Rhode Island Red; CN, Cornish.

Table 3. Within population $\left(F_{\mathrm{IS}}\right)$, between populations $\left(F_{\mathrm{ST}}\right)$ and overall population $\left(F_{\mathrm{IT}}\right)$ inbreeding coefficients and their standard errors of Korean native and imported chicken populations

\begin{tabular}{lccc}
\hline Population & $F_{\text {IS }}$ & $F_{\text {ST }}$ & $F_{\text {IT }}$ \\
\hline Korean native & $0.105 \pm 0.028$ & $0.142 \pm 0.010$ & $0.234 \pm 0.025$ \\
Imported & $0.134 \pm 0.027$ & $0.351 \pm 0.021$ & $0.438 \pm 0.024$ \\
Overall & $0.113 \pm 0.025$ & $0.218 \pm 0.012$ & $0.307 \pm 0.021$ \\
\hline
\end{tabular}

Korean native chicken flocks $(0.105 \pm 0.028)$.

\section{Genetic difference and distance among breeds}

The Nei's $D_{\text {A }}$ genetic distance is basically a correlation among the allele frequencies between breeds. Table 4 shows $D_{\text {A }}$ genetic distance between each pair for all nine chicken breeds, based on 30 microsatellite loci genotypes. The genetic distance ranges from 0.161 (KR and KY) to 0.450 (WL and RI). The genetic distance among five Korean native breeds (KR, KY, KG, KB, and $\mathrm{KW}$ ) were also found to be quite low (0.161 to 0.243). Figure 1 shows a phylogenetic tree of nine chicken breeds that was constructed from $D_{\mathrm{A}}$ genetic distances by using the unweighted pair group method with average linkages (UPGMA) dendrogram. Five Korean native breeds clustered together under one group, and formed a close group with RI. The WL culminates on a different node forming the out-group.

\section{Cluster analysis}

The analysis in STRUCTURE revealed that nine breeds should be divided in nine clusters (Figure 2) based on the highest $\Delta K$ value (data was not shown) according to Evanno et al. (2005). The KR, KY, KG, KW, WL, RI, and CN were each grouped in their own cluster with an estimated membership value higher than 0.90 (Table 5). The KO did also group in the own cluster but show relatively low estimated membership value (0.738).

\section{DISCUSSION}

The $F_{\text {IS }}$ represents a degree of nonrandom mating (deviation from Hardy-Weinberg equilibrium). A positive number for $F_{\text {IS }}$ means a deviation from Hardy-Weinberg equilibrium. Seven out of 30 markers named ADL0278, LEI0094, LEI0096, LEI0209, MCW0016, MCW0214, and MCW0252 showed a negative number. However, all the others showed a positive number. This result indicated that

Table 4. Nei's $D_{\mathrm{A}}$ genetic distance (Nei et al., 1983) among the nine chicken populations

\begin{tabular}{|c|c|c|c|c|c|c|c|c|c|}
\hline & KR & $\mathrm{KY}$ & $\mathrm{KG}$ & $\mathrm{KB}$ & KW & $\mathrm{KO}$ & WL & RI & $\mathrm{CN}$ \\
\hline$\overline{\mathrm{KR}}$ & - & & & & & & & & \\
\hline $\mathrm{KY}$ & 0.161 & - & & & & & & & \\
\hline $\mathrm{KG}$ & 0.223 & 0.181 & - & & & & & & \\
\hline $\mathrm{KB}$ & 0.187 & 0.192 & 0.243 & - & & & & & \\
\hline KW & 0.243 & 0.176 & 0.191 & 0.226 & - & & & & \\
\hline $\mathrm{KO}$ & 0.235 & 0.243 & 0.310 & 0.256 & 0.323 & - & & & \\
\hline WL & 0.392 & 0.394 & 0.409 & 0.381 & 0.408 & 0.349 & - & & \\
\hline RI & 0.231 & 0.264 & 0.259 & 0.262 & 0.297 & 0.308 & 0.450 & - & \\
\hline $\mathrm{CN}$ & 0.276 & 0.272 & 0.258 & 0.272 & 0.293 & 0.253 & 0.397 & 0.348 & - \\
\hline
\end{tabular}

KR, Korean Reddish Brown; KY, Korean Yellowish Brown; KG, Korean Grayish Brown; KB, Korean Black; KW, Korean White; KO, Korean Ogye; WL, White Leghorn; RI, Rhode Island Red; CN, Cornish. 


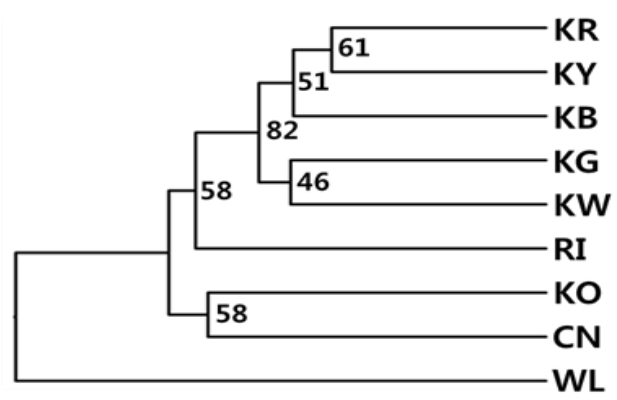

Figure 1. UPGMA dendrogram of genetic among nine chicken breeds based on $D_{\text {A }}$ genetic distances (Nei et al., 1983) estimated with 30 microsatellites. Numbers on the nodes are bootstrap values of 1000 replications. KR, Korean Reddish Brown; KY, Korean Yellowish Brown; KB, Korean Black; KG, Korean Grayish Brown; KW, Korean White; RI, Rhode Island Red; KO, Korean Ogye; CN, Cornish; WL, White Leghorn.

nonrandom mating was performed in Korean chicken breeds studied in the present analysis. It is known that these breeds were extensively crossbred in the earlier years until 1970 when the government realized the importance of pure native breeds and started a program where the native breeds were re-bred within same strains to recover the pure strains (Kong et al., 2006). The mean $F_{\text {ST }}$ value of 0.218 indicates that approximately $21.8 \%$ of the total genetic variation is caused by breed differences, whereas the remaining $87.2 \%$ is due to differences among individuals within breeds. White leghorn exhibited a lower degree of genetic diversity (mean number of alleles $[\mathrm{MNA}]=3.43, H_{\mathrm{Exp}}=0.416, H_{\mathrm{Obs}}$ $=0.326$, PIC $=0.371$ ) than all other breeds in all measures of genetic diversity whereas a high degree of diversity was observed in KR $\left(\mathrm{MNA}=5.43, H_{\mathrm{Exp}}=0.624, H_{\mathrm{Obs}}=0.548\right.$, $\mathrm{PIC}=0.575)$ and $\mathrm{KB}\left(\mathrm{MNA}=5.17, H_{\mathrm{Exp}}=0.629, H_{\mathrm{Obs}}=\right.$ 0.591 , PIC $=0.569$ ). Heterozygosity was observed for WL as quite low compared to other breeds which may be due to inbreeding among closely related birds. High diversity in Korean native chicken breed may be attributed to breeding among large number of individuals in a wider and different geographical locations.

Heterozygosity estimates within the population were based on a set of markers showing substantial heterogenity in the NA detected and in the PIC (Wimmers et al., 2000). There are difficulties in comparing the present results with previous study results, as they were obtained with different marker sets. Even though they have been obtained with different marker sets, the $H_{\text {Exp }}$ and PIC (0.696 and 0.653) values observed in Korean chicken breeds were found to be higher than reported by Tadano et al. (2007) for Japanese chicken breeds $\left(H_{\operatorname{Exp}}=0.432\right.$ and PIC $\left.=0.373\right)$ and Wilkinson et al. (2012) for 24 British chicken breeds $\left(H_{\operatorname{Exp}}\right.$ $=0.49$ ). Whereas the values for $H_{\operatorname{Exp}}$ and PIC reported by Kong et al. (2006) for Korean chicken breeds $\left(H_{\operatorname{Exp}}=0.630\right.$ and PIC $=0.552)$, Kaya and Yildiz (2008) for Turkish breeds $\left(H_{\text {Exp }}=0.665\right.$ and PIC $\left.=0.610\right)$ and Chen et al. (2008) for 15 Chinese breeds $\left(H_{\operatorname{Exp}}=0.644\right)$ were almost

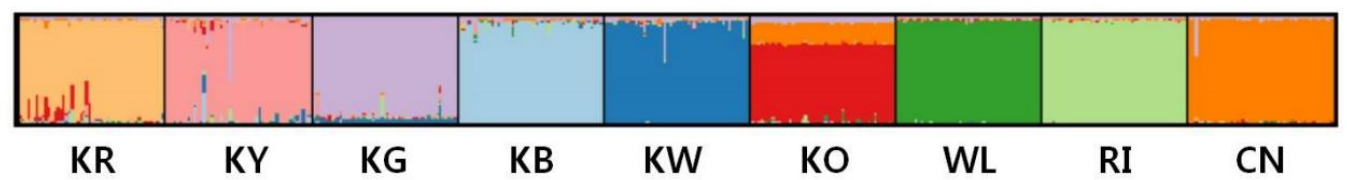

Figure 2. Clustering assignment of the nine chicken populations obtained by STRUCTURE analysis. Each of the 450 birds is represented by a thin vertical line, which is divided into colored segments which represent the proportional contribution of the inferred $K=9$ clusters. The populations are separated by thin vertical black lines. KR, Korean Reddish Brown; KY, Korean Yellowish Brown; KG, Korean Grayish Brown; KB, Korean Black; KW, Korean White; KO, Korean Ogye; WL, White Leghorn; RI, Rhode Island Red; CN, Cornish.

Table 5. Population of membership of each the nine chicken population genotypes with the 30 microsatellite markers in the nine inferred clusters using STRUCTURE analysis

\begin{tabular}{|c|c|c|c|c|c|c|c|c|c|c|}
\hline \multirow{2}{*}{ Breed } & \multicolumn{9}{|c|}{ Inferred clusters } & \multirow{2}{*}{$\begin{array}{l}\text { Number of } \\
\text { individuals }\end{array}$} \\
\hline & 1 & 2 & 3 & 4 & 5 & 6 & 7 & 8 & 9 & \\
\hline$\overline{\mathrm{KR}}$ & $0.900^{1}$ & 0.011 & 0.006 & 0.009 & 0.005 & 0.048 & 0.004 & 0.009 & 0.007 & 50 \\
\hline KY & 0.008 & 0.904 & 0.024 & 0.016 & 0.019 & 0.010 & 0.003 & 0.009 & 0.007 & 50 \\
\hline KG & 0.003 & 0.010 & 0.919 & 0.003 & 0.043 & 0.006 & 0.004 & 0.008 & 0.004 & 50 \\
\hline KB & 0.005 & 0.007 & 0.007 & 0.948 & 0.005 & 0.005 & 0.006 & 0.013 & 0.004 & 50 \\
\hline KW & 0.004 & 0.007 & 0.020 & 0.004 & 0.950 & 0.003 & 0.002 & 0.006 & 0.005 & 50 \\
\hline $\mathrm{KO}$ & 0.004 & 0.004 & 0.042 & 0.004 & 0.003 & 0.738 & 0.009 & 0.005 & 0.192 & 50 \\
\hline WL & 0.002 & 0.002 & 0.002 & 0.003 & 0.002 & 0.002 & 0.983 & 0.002 & 0.002 & 50 \\
\hline RI & 0.003 & 0.003 & 0.002 & 0.003 & 0.002 & 0.004 & 0.002 & 0.978 & 0.003 & 50 \\
\hline $\mathrm{CN}$ & 0.002 & 0.002 & 0.011 & 0.002 & 0.002 & 0.004 & 0.003 & 0.003 & 0.971 & 50 \\
\hline
\end{tabular}

KR, Korean Reddish Brown; KY, Korean Yellowish Brown; KG, Korean Grayish Brown; KB, Korean Black; KW, Korean White; KO, Korean Ogye; WL, White Leghorn; RI, Rhode Island Red; CN, Cornish.

${ }^{1}$ Contribution higher than 0.900 are in bold. 
similar to or slightly higher than the values obtained for the present analysis. These results indicated Korean native chicken (KNC) breeds have kept a high level of genetic diversity.

In the phylogenetic tree, the $\mathrm{KNC}$ breeds showed a close relationship, with the exception of the KO breed. The $\mathrm{RI}$ appeared genetically closer to the KNC breeds, whereas WL was genetically distinct from other breeds.

Bayesian clustering approaches gives more accurate information on breed relationships (Leroy et al., 2008). The $\Delta K$ statistic was obviously at a maximum at $K=9$, which suggest the most probable number of inferred clusters $(K=$ 9). As well the results support the upshot of the analysis by Seo et al. (2013) where in five Korean native chicken breeds five underlying genetic clusters were identified. The results revealed that Korean chicken breeds are continuing without introgression of imported breeds.

The current study is the first detailed analysis based on the $30 \mathrm{MS}$ marker polymorphisms of the genetic diversity in the six Korean native chicken breeds which have been recognized by the DAD-IS of the FAO (http://dad.fao.org/). The knowledge obtained regarding Korean chicken breeds as estimated by microsatellite analysis may also be useful as an initial guide in defining objectives for designing future investigations of genetic variation and developing conservation strategies.

\section{ACKNOWLEDGMENTS}

This work was carried out with the support of "Cooperative Research Program for Agriculture Science \& Technology Development (Project No. PJ006973012011)" Rural Development Administration, Republic of Korea. This study was supported by 2014 Postdoctoral Fellowship Program of National Institute of Animal Science, Rural Development Administration, Republic of Korea.

\section{REFERENCES}

Chen, G., W. Bao, J. Shu, C. Ji, M. Wang, H. Eding, F. Muchadeyi, and S. Weigend. 2008. Assessment of population structure and genetic diversity of 15 Chinese indigenous chicken breeds using microsatellite markers. Asian Australas. J. Anim. Sci. 21:331-339.

Crooijmans, R. P. M. A., J. V. D. Poel, and M. A. M. Groenen. 1995. Functional genes mapped on the chicken genome. Anim. Gent. 26:73-78.

Dunnington, E. A., L. C. Stallard, J. Hillel, and P. B. Siegel. 1994. Genetic diversity among commercial chicken populations estimated from DNA fingerprints. Poult. Sci. 73:1218-1225.

Earl, D. A. and B. M. von-Holdt. 2012. STRUCTURE HARVESTER: A website and program for visualizing STRUCTURE output and implementing the Evanno method. Conserv. Genet. Resour. 4:359-361.
Evanno, G., S. Regnaut, and J. Goudet. 2005. Detecting the number of clusters of individuals using the software STRUCTURE: A simulation study. Mol. Ecol. 14:2611-2620.

FAO/MoDAD. 2004. Secondary Guidelines. Measurement of Domestic Animal Diversity (MoDAD): Recommended Microsatellite Markers. Available at http://fao.org/dad-is

Goudet, J. 2001. FSTAT, a program to estimate and test gene diversities and fixation indices (ver. 2.9.3.) Lausanne (Switzerland). Institute of Ecology. Available at http://www2.unil.ch/popgen/softwares/fstat.html

Hillel, J., M. A. Groenen, M. Tixier-Boichard, A. B. Korol, L. David, V. M. Kirzhner, T. Burke, A. Barre-Dirie, R. P. M. A. Crooijmans, K. Elo, M. W. Feldman, P. J. Freidlin, A. MäkiTanila, M. Oortwijn, P. Thomoson, A. Vignal, K. Wimmers, and S. Weigend. 2003. Biodiversity of 52 chicken populations assessed by microsatellite typing of DNA pools. Genet. Sel. Evol. 35:533-557.

Jakobsson, M. and N. A. Rosenberg. 2007. CLUMPP: A cluster matching and permutation program for dealing with label switching and multimodality in analysis of population structure. Bioinformatics 23:1801-1806.

Kalinowski, S. T., M. L. Taper, and T. C. Marshall. 2007. Revising how the computer program CERVUS accommodates genotyping error increases success in paternity assignment. Mol. Ecol. 16:1099-1106.

Kaya, M. and M. A. Y1ldiz. 2008. Genetic diversity among Turkish native chickens, Denizli and Gerze, estimated by microsatellite markers. Biochem. Genet. 46:480-491.

Kong, H. S., J. D. Oh, J. H. Lee, K. J. Jo, B. D. Sang, C. H. Choi, S. D. Kim, S. J. Lee, S. H. Yeon, G. J. Jeon, and H. K. Lee. 2006. Genetic variation and relationships of Korean native chickens and foreign breeds using 15 microsatellite markers. Asian Australas. J. Anim. Sci. 19:1546-1550.

Leroy, G., E. Verrier, J. C. Meriaux, and X. Rognon. 2009. Genetic diversity of dog breeds: Between-breed diversity, breed assignation and conservation approaches. Anim. Genet. 40:333-343.

MAF (Ministry of Agriculture and Forestry, Republic of Korea). 2004. National report on the state of animal genetic resources. Seoul, Rep of Korea. p. 23. Available at: $\mathrm{ftp} / / / \mathrm{ftp}$.fao.org/docrep/fao/010/a1250e/annexes/CountryRepor ts/KoreanRepublic.pdf

Muchadeyi, F. C., H. Eding, C. B. A. Wollny, E. Groeneveld, S. M. Makuza, R. Shamseldin, H. Simianer, and S. Weigend. 2007. Absence of population substructuring in Zimbabwe chicken ecotypes inferred using microsatellite analysis. Anim. Genet. 38:332-339.

Nei, M., F. Tajima, and Y. Tateno. 1983. Accuracy of estimated phylogenetic trees from molecular data. J. Mol. Evol. 19:153170.

Osman, S. A. M., M. Sekino, A. Nishihata, Y. Kobayashi, W. Takenaka, K. Kinoshita, T. Kuwayama, M. Nishibori, Y. Yamamoto, and M. Tsudzuki. 2006. The genetic variability and relationships of Japanese and Foreign chickens assessed by microsatellite DNA profiling. Asian Australas. J. Anim. Sci. 19:1369-1378.

Ota, T. 1993. DISPAN. Pennsylvania State University, PA, USA. Peakall, R. O. D. and P. E. Smouse. 2006. GENALEX 6: genetic 
analysis in Excel. Population genetic software for teaching and research. Mol. Ecol. Notes 6:288-295.

Pritchard, J. K., M. Stephens, and P. Donnelly. 2000. Inference of population structure using multilocus genotype data. Genetics 155:945-959.

Rosenberg, N. A. 2004. DISTRUCT: A program for the graphical display of population structure. Mol. Ecol. Notes 4:137-138.

Seo, D. W., M. R. Hoque, N. R. Choi, H. Sultana, H. B. Park, K. N. Heo, B. S. Kang, H. T. Lim, S. H. Lee, C. Jo, and J. H. Lee. 2013. Discrimination of Korean Native chicken lines using fifteen selected microsatellite markers. Asian Australas. J. Anim. Sci. 26:316-322.

Smith, E. J., S. A. Ray, M. R. Bakst, C. Teuscher, and T. F. Savage. 1996. Simple sequence repeat-based single primer amplification of genomic DNA in random bred populations of turkeys and chickens. Anim. Biotechnol. 7:47-58.
Tadano, R., M. Sekino, M. Nishibori, and M. Tsudzuki. 2007. Microsatellite marker analysis for the genetic relationships among Japanese long-tailed chicken breeds. Poult. Sci. 86:460469.

Vanhala, T., M. Tuiskula-Haavisto, K. Elo, J. Vilkki, and A. MakiTanila. 1998. Evaluation of genetic variability and genetic distances between eight chicken lines using microsatellite markers. Poult. Sci. 77:783-790.

Weir, B. S. and C. C. Cockerham. 1984. Estimating F-statistics for the analysis of population structure. Evolution 38:1358-1370.

Wilkinson, S., P. Wiener, D. Teverson, C. S. Haley, and P. M. Hocking. 2012. Characterization of the genetic diversity, structure and admixture of British chicken breeds. Anim. Genet. 43:552-563.

Wimmers, K., S. Ponsuksili, T. Hardge, A. Valle-Zarate, P. K. Mathur, and P. Horst. 2000. Genetic distinctness of African, Asian and South American local chickens. Anim. Genet. 31:159-165. 